\title{
The Timing of Sexual Debut Among Chinese Youth
}

By Wei Guo, Zheng Wu, Yue Qiu, Gong Chen and Xiaoying Zheng

Wei Guo, lecturer, School of Social and Behavioral Sciences, Nanjing University, Nanjing, People's Republic of China, was a doctoral student at Peking University,

Beijing, at the time this article was being written. Zheng $\mathrm{Wu}$ is professor, Department of Sociology, University of Victoria, Victoria, British Columbia, Canada. Yue Qiu is a doctoral candidate, Gong Chen is professor, and

Xiaoying Zheng is professor and director, all at the Institute of Population Research,

Peking University, Beijing, People's Republic of China.

CONTEXT: The age at sexual debut is declining in China, but little is known about the relationship between the social and demographic characteristics of Chinese youth and the timing of debut.

METHODS: Data were drawn from the 2009 National Youth Reproductive Health Survey, which collected background information and age at sexual debut from 22,300 unmarried youth aged 15-24. Life table analysis was used to estimate the gender-specific distributions of sexual debut by age, according to urban or rural residence and by region. Cox proportional hazard regression models were then employed to identify characteristics associated with the timing of debut among males and females.

RESULTS: The mean age at sexual debut was 22.8 years (22.5 years for men and 23.1 years for women). Sexual debut before age 18 was rare for both genders, and ages 21-24 appear to be the normative range for sexual debut. Life table analysis found that debut was earlier for males than for females, for those living in a rural area than for those in urban areas, and for those living in western China than for those in other regions. In multivariate hazard regression analysis, males had a 30\% greater risk of experiencing sexual debut within each year of age than did females. Living in a household with both biological parents, having a father with a junior or senior high school education, being a college graduate and living in an urban area were associated with a reduced risk of experiencing sexual debut.

CONCLUSION: This study provides insight into the basic patterns and social and demographic correlates of sexual debut among Chinese youth.

International Perspectives on Sexual and Reproductive Health, 2012, 38(4):196-204, doi: 10.1363/3819612

Little is known about social variations in the timing of sexual debut in China. In many Western societies, the age at sexual debut began to decline during the 1970s with the relaxation of attitudes about premarital sex. ${ }^{1}$ The decline in the age at debut and the increase in the proportion of youth who have had sexual intercourse generated considerable research interest in the social and demographic characteristics associated with sexual debut; ${ }^{2,3}$ for example, there is substantial variation in the timing of debut between males and females, by ethnic or racial group, and by social class.

A better understanding of the social differences in timing of sexual debut is essential for identifying groups who may have an increased likelihood of engaging in risky sexual behaviors. In China, there are 150 million unmarried youth aged $15-24,{ }^{4}$ but little is known about their sexual behavior. Even though attitudes about sexual relationships and sex outside marriage have become more relaxed in the country, there remains a general reluctance to openly discuss sex, especially with youth, who consequently tend to be ill-informed about their sexual and reproductive health. ${ }^{5-7}$ With the increase in the percentage of youth engaging in premarital sex, the issue of risky sexual behavior among China's adolescent and young adult population is a growing concern. 8,9

\section{BACKGROUND \\ The Chinese Context}

During the Maoist period-from the 1950s to the mid1970s-sex was regarded by the Chinese government as a "bourgeois indulgence" and sexual relations outside marriage were discouraged..$^{10}$ Prior to 1980 , marriage was illegal before age 23 for women and 25 for men living in rural areas, and before ages 25 and 28 for their urban counterparts. ${ }^{11}$ Parish and coauthors have demonstrated that trends in sexual behavior in China since 1950 are inseparable from changes in administrative policies, such as marriage laws and birth planning policies. ${ }^{12}$ From the 1950 s to the 1970s, the age at sexual debut rose, not only because of the government's regulation of sexual relations and reproduction, but also because of traditional attitudes about sex. Indeed, sexual relations were strongly linked to marriage, the family and procreation, which limited people's autonomy over their sexual desires and behaviors. ${ }^{13-16}$

The subsequent liberalization of China is partly a consequence of the Deng Xiaoping administration's "Open Door" policy, beginning in the late 1970 s, ${ }^{13,14,17}$ when the state lowered the legal age of marriage to 20 for women and 22 for men. In addition, the implementation of state family planning policies and the promotion and distribution of contraceptive methods under the one-child poli- 
cy, ${ }^{13}$ which was introduced in 1978 , delinked sexual intercourse from procreation and fueled the notion that sex could be engaged in primarily for pleasure. Yet even in the 1990s, only about one-quarter of Chinese youth had had sex by age $20 .^{12}$

In recent decades, the age at sexual debut has declined and premarital sex has become more common. ${ }^{18}$ Data from the 2009 National Youth Reproductive Health Survey demonstrate that $60 \%$ of unmarried youth are willing to have premarital sex and $22 \%$ have done so. ${ }^{19}$ These data also reveal a widespread lack of knowledge about contraception and STI prevention; about half of Chinese youth did not use any form of contraception or protection at sexual debut. Furthermore, 23\% of sexually active unmarried women have had an unwanted pregnancy, and 91\% of them subsequently had an abortion. In addition, more than half of all STIs in China occur among those aged 29 or younger. ${ }^{20}$ Sex education programs have been offered in schools since 1985, but these have generally not addressed the reduction of high-risk behaviors among youth. ${ }^{6,21}$ Indeed, the curriculum focuses on basic facts about reproduction, and discussion of contraception tends to be excluded out of concern that it could be seen as promoting sexual activity among youth.

\section{Determinants of Sexual Debut}

Both biological characteristics (e.g., age at puberty) and social opportunities (e.g., dating) influence the age at sexual debut, ${ }^{22,23}$ but these variables alone are insufficient for explaining the variation in the timing of debut. An individual's psychosocial readiness for sexual intercourse and relevant social and demographic characteristics also play an important role. We are interested in the social and demographic differences among youth regarding the timing of sexual debut, and focus on characteristics examined in earlier research that were also assessed in this national survey. Given the paucity of such research in China, this study draws mainly from Western-based research for guidance. Although the characteristics associated with the timing of debut may be culturally sensitive, the following variables are likely relevant for Chinese youth.

- Gender. Sexual debut is more problematic for females than for males, as the former may experience more negative consequences from early debut, such as social stigma, depression, unwanted pregnancy and abortion. ${ }^{24,25}$ Singh et al. examined gender differences in the age at sexual debut in 14 countries from five continents, ${ }^{26}$ and found that-except in Africa-a higher proportion of males than of females reported having had sex before age 17, and males' median age of debut was lower. Moreover, for males, sexual debut during the teenage years tended to occur outside of marriage, whereas it occurred within marriage for females. Chinese society continues to emphasize the importance of premarital virginity for females, ${ }^{13,15}$ hence we anticipate that the timing of debut will be earlier for males than for females.

- Family structure. The relationship between age at sexual
TABLE 1. Percentage distribution of unmarried youth aged 15-24, by selected characteristics, National Youth Reproductive Health Survey, China, 2009

Characteristic All

A

Age

15-16

$17-20$

21-24

49.1

Gender

Male

All

$=22,288)$

Female

50.8

Current activity

In school

Family structure

Household with both biological parents $\quad 94.4$

Other

5.6

Father's education

selementary school $\quad 14.2$

Junior high school

Senior high/technical schoolt $\quad 32.6$

$\geq$ college

15.8

Mother's education

selementary school $\quad 25.5$

Junior high school $\quad 38.0$

Senior high/technical school $† \quad 24.8$

$\geq$ college

11.7

Respondent's education

sjunior high school

18.3

Senior high/technical schoolt

56.4

$\geq$ college

25.3

Received formal sex education

Yes

34.8

No

65.2

Residence

Rural

Urban

51.5

48.5

Region

Eastern

Central

45.6

Western

31.4

23.0

Total

100.0

†For students who have finished junior high school. Note: Percentages are weighted.

debut and family structure is well established. In urban China, adolescents who live with both biological parents are less likely than those who live with a single parent or in stepfamilies to have had sex. ${ }^{8}$ This pattern is consistent with findings from Western countries. ${ }^{27-29}$ Furthermore, the role of family structure appears to be context- and gender-dependent. In a U.S. study, Santelli et al. found that living in a single-father household was associated with an increased risk of early debut for males and females, while living in a single-mother household had a weaker association for females and none for males. ${ }^{30}$ Newcomer and Udry argued that differences in parental control and time available for tending to children's emotional needs could explain such household-level differences. ${ }^{31}$ Divorce is rare 


\begin{tabular}{|c|c|c|c|c|}
\hline \multirow[t]{2}{*}{ Characteristic } & \multicolumn{2}{|l|}{ Male } & \multicolumn{2}{|l|}{ Female } \\
\hline & $\mathrm{N}$ & $\%$ & $N$ & $\%$ \\
\hline \multicolumn{5}{|l|}{ Age } \\
\hline $15-16$ & 2,180 & 5.0 & 2,284 & 2.8 \\
\hline $17-20$ & 5,406 & 17.4 & 5,643 & 12.9 \\
\hline $21-24$ & 3,626 & 46.1 & 3,149 & 39.3 \\
\hline \multicolumn{5}{|l|}{ Gender } \\
\hline Male & 11,212 & 25.5 & na & na \\
\hline Female & na & na & 11,076 & 19.2 \\
\hline \multicolumn{5}{|l|}{ Current activity } \\
\hline In school & 5,221 & 14.4 & 5,861 & 8.9 \\
\hline Working/unemployed & 5,991 & 34.6 & 5,215 & 28.3 \\
\hline \multicolumn{5}{|l|}{ Family structure } \\
\hline Household with both & & & & \\
\hline biological parents & 10,509 & 25.1 & 10,422 & 18.8 \\
\hline Other & 703 & 30.2 & 654 & 27.1 \\
\hline \multicolumn{5}{|l|}{ Father's education } \\
\hline selementary school & 1,273 & 29.2 & 1,252 & 21.9 \\
\hline Junior high school & 3,909 & 24.7 & 3,893 & 19.0 \\
\hline Senior high/technical school† & 3,853 & 25.7 & 3,743 & 18.2 \\
\hline$\geq$ college & 2,177 & 23.3 & 2,188 & 19.3 \\
\hline \multicolumn{5}{|l|}{ Mother's education } \\
\hline selementary school & 3,109 & 25.3 & 3,183 & 21.2 \\
\hline Junior high school & 4,080 & 26.4 & 4,059 & 18.9 \\
\hline Senior high/technical school† & 2,365 & 24.9 & 2,262 & 18.2 \\
\hline$\geq$ college & 1,658 & 23.8 & 1,572 & 17.8 \\
\hline \multicolumn{5}{|l|}{ Respondent's education } \\
\hline sjunior high school & 1,688 & 27.0 & 1,607 & 19.8 \\
\hline Senior high/technical schoolt & 6,392 & 20.9 & 6,271 & 16.6 \\
\hline$\geq$ college & 3,132 & 34.6 & 3,198 & 24.4 \\
\hline \multicolumn{5}{|l|}{ Received formal sex education } \\
\hline Yes & 4,340 & 26.7 & 4,872 & 19.9 \\
\hline No & 6,872 & 24.8 & 6,204 & 18.8 \\
\hline \multicolumn{5}{|l|}{ Residence } \\
\hline Rural & 6,536 & 25.7 & 6,414 & 20.2 \\
\hline Urban & 4,676 & 25.1 & 4,662 & 18.2 \\
\hline \multicolumn{5}{|l|}{ Region } \\
\hline Eastern & 6,134 & 24.5 & 6,113 & 19.3 \\
\hline Central & 2,854 & 24.9 & 2,764 & 18.6 \\
\hline Western & 2,224 & 28.1 & 2,199 & 19.8 \\
\hline
\end{tabular}

tFor students who had finished junior high school. Notes: Ns are unweighted, and percentages are weighted. na=not applicable.

in China, and the little research that has been conducted suggests that it has negative effects on children's well-being and behavior, ${ }^{32}$ largely because of societal discrimination against divorced families, which deprives children of familial resources and makes adjustment difficult. Hence, we expect that living in a nonconventional household will be associated with an elevated risk of experiencing earlier sexual debut.

- Parental education. Numerous studies have demonstrated a strong relationship between parental education and timing of sexual debut, ,23,33 and this relationship can function through several pathways. ${ }^{24}$ Foremost, parental education is a proxy for household socioeconomic status, which is often associated with differences in risk-taking be- havior; it also influences adolescents' access to information about sex, medical advice and contraception. In addition, because risk-taking has different implications depending on one's socioeconomic status, the opportunity costs (e.g., pregnancy) likely rise with such status, given that adolescents from better-off families have greater access than others to postsecondary education, and perhaps higher expectations from parents to establish careers before becoming parents themselves. Our expectation is that higher levels of parental education will be associated with the postponement of sexual debut among Chinese youth.

- Formal sex education. Kohler and coauthors found that in the United States, receipt of comprehensive sex education was negatively associated with the risk of having ever had sex and having had a teenage pregnancy. ${ }^{34}$ However, abstinence-only sex education was not associated with either of these measures, indicating that the content of sex education is crucial. In another U.S. study, Mueller et al. demonstrated that adolescents who had received sex education postponed their sexual debut and reported increased use of contraceptives at first sex. ${ }^{35}$ As discussed earlier, many Chinese youth have limited knowledge about sexual and reproductive health, especially contraception and STI protection. Moreover, youth from lower socioeconomic and rural households appear to have the least knowledge. ${ }^{9}$ We predict that a lack of sex education will be associated with earlier sexual debut among Chinese adolescents.

- Community setting. This study also considers differences in the timing of sexual debut depending on urban versus rural residence, as well as by region. The official household registration system controls population movement in China and is a source of social conflict. Those with rural registration have comparatively limited access to educational opportunities and almost no access to public employment, health care and pensions. ${ }^{36}$ Furthermore, regional imbalances in development exist because reformera economic policies favored the modernization and industrialization of the eastern (coastal) regions. ${ }^{37}$ The intuitive assumption is that premarital sex is more common in urban and well-developed regions, largely because these areas have experienced greater social change. However, it is not clear that social institutions and norms are more prohibitive in rural and less developed regions. A study from the late 1980s found that premarital sex was less prevalent in these regions-where nonvirginity has relatively high costs for women in the marriage market ${ }^{38}$-but this may no longer be true. ${ }^{5}$ Changes in sexual norms appear to be leading to a decline in the age at sexual debut in rural areas, but the prevalence of premarital sex has increased more in urban areas, perhaps because of earlier age at marriage in rural areas. ${ }^{12,39}$ While it remains unclear how the community setting might influence the timing of sexual debut among unmarried youth, it appears to be a potentially important determinant.

The current study examines the social variations in timing of sexual debut among unmarried Chinese youth aged 
15-24, and focuses on the gender-specific differences in timing. We used data from the 2009 National Youth Reproductive Health Survey, the first nationally representative survey on the sexual behaviors of Chinese youth. Earlier studies on the timing of sexual debut and characteristics associated with it were based on area or regional samples, which did not yield generalizable findings. ${ }^{40,41}$ This previous absence of adequate national data limited our knowledge about adolescent sexual behavior. Another motivation for this effort is the well-established finding that the age at sexual debut is an indicator of exposure to STIs and other undesirable outcomes, ${ }^{27,42-44}$ particularly unwanted pregnancy and HIV infection among 15-24-year-olds.

\section{METHODS}

Data

Data from the National Youth Reproductive Health Survey-a collaboration of Peking University, the National Working Committee on Children and Women under the State Council and the United Nations Population Fundwere collected by Peking University in October and November of 2009. The target population was unmarried youth aged 15-24 who were living in a mainland province, autonomous region or municipality; youth living in Tibet, which has less than $0.2 \%$ of China's total population, were excluded. ${ }^{4}$ The survey used a multistage sampling design. The country was initially divided into seven geographic regions, from which 40 administrative regions were selected, using probability proportional to size (PPS). The target population in these latter regions was further divided into three groups: in-school youth, out-of-school youth and youth living in collective households. The third group included primarily those who were working and living in company dormitories.

For in-school youth, a sample of schools (junior high schools, senior high and technical schools, and colleges) was selected in each administrative region, followed by a sample of students from each school. For out-of-school youth, a sample of counties and municipalities was selected in each region using PPS, and the same method was employed to identify a sample of neighborhoods and villages; households were then selected from each neighborhood or village, and respondents were selected from these households. For youth living in collective households, in each selected county or municipality, a sample of dormitories was selected using an area sampling method, and then youth were selected from each dormitory. For all three groups combined, a total of 22,288 individuals completed interviews, for an overall response rate of $75 \% .{ }^{45}$

\section{Dependent Variable}

To determine the timing of sexual debut, respondents were asked, "How old were you (in years) when you had sexual intercourse for the very first time?" To protect confidentiality and reduce nonresponses, the responses from this section of the interview were collected via a paper questionnaire, which the respondents completed in pri-
|FIGURE 1. Survival distributions of sexual debut among Chinese youth, by gender

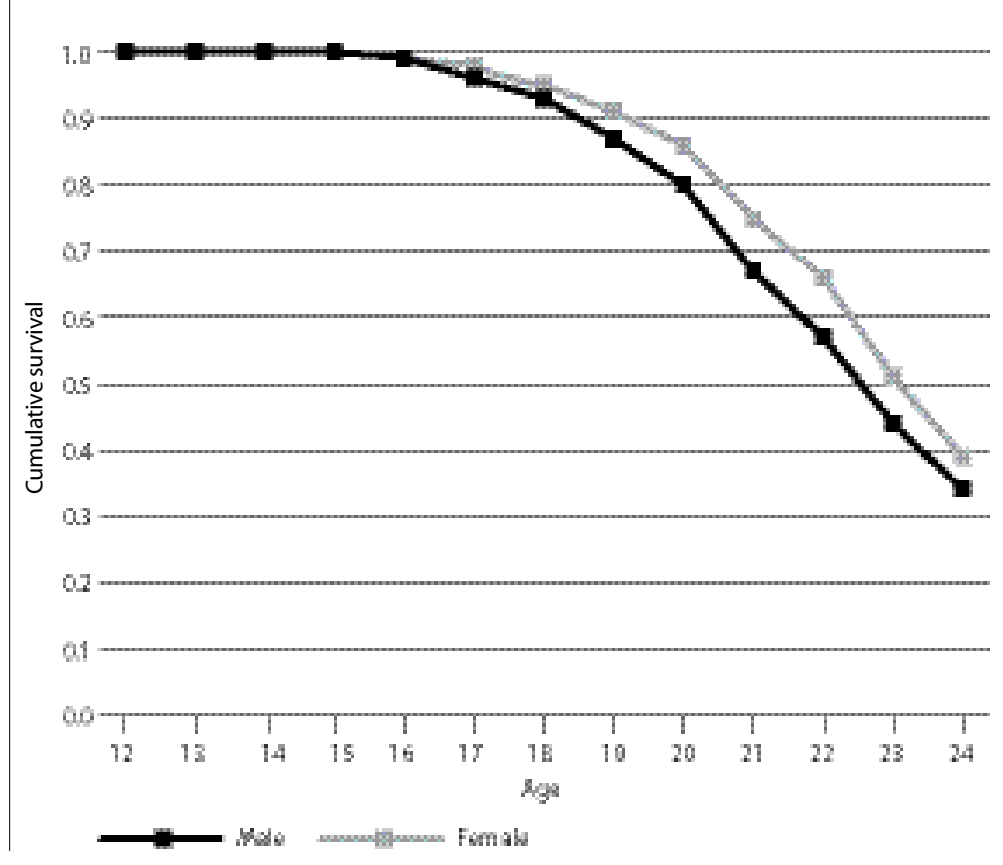

vate. Because sexual debut is a milestone life course experience and people are likely to remember accurately at what age it occurred, ${ }^{25,46}$ recall errors tend to be random and have minimal impact on estimates. The variable was right-censored for respondents who had not had sexual intercourse by the time of the survey.

\section{Independent Variables}

These variables included age, gender, family structure, parental education, receipt of formal sex education, educational attainment and two community-level variablesurban or rural residence, and geographic region. The survey classified youths into three subpopulations: those who were currently in school; those who were currently working or unemployed and lived in private households (mostly their parents' home); and those who were employed and living in collective dwellings, such as a workplace dormitory. In the analysis, the latter two groups were combined and designated as the reference group.

Family structure is a measure of whether the respondent was living in a household with both biological parents (or had been before moving out) or in another situation, such as a household with a single parent or stepparent. Father's and mother's education was a four-category variable of the level completed: elementary school or less, junior high school, senior high school or technical school, and at least college. Respondents' educational attainment was classified into three categories: junior high school or less, senior high or technical school, and at least college. Receipt of formal sex education was a dichotomous variable indicating whether individuals had experienced such a program in school.

In China, a person's household registration status (hukou) represents their official residence classification as 
FIGURE 2. Survival distributions of sexual debut among Chinese youth, by gender and residence
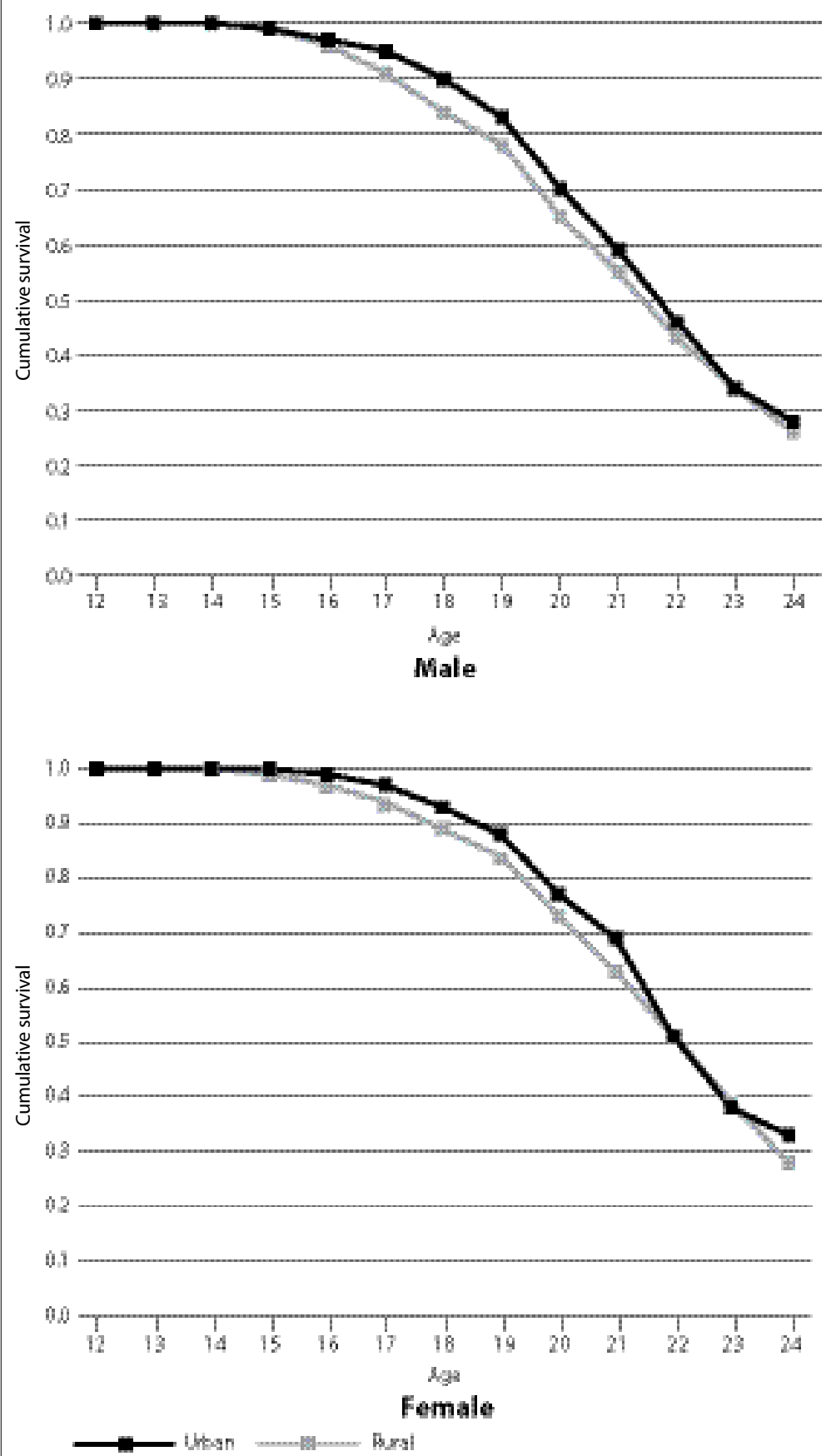

either "agricultural" (rural) or "nonagricultural" (urban), and it determines where people can permanently reside and their access to public resources. Finally, region of residence was classified as eastern, central or western China.

\section{Analysis}

We first determined the percentages of males and females who were sexually experienced, by age and other characteristics. We then used life table techniques to estimate the survival distributions of sexual debut by gender, urban or rural setting, and region. These estimates are nonpara- metric and not subject to biases arising from violations of distributional assumptions of the underlying hazard. Logranked tests for equality of function were performed to demonstrate whether the differences in the survival plots were statistically significant. Finally, in the multivariate survival analysis, Cox proportional hazard regression analysis was employed to calculate hazard ratios for the timing of sexual debut by gender ${ }^{47}$ because of the nature of the multistage sampling design, we generated robust standard errors to account for possible clustering effects.

\section{RESULTS}

Eighteen percent of respondents were aged 15-16, while $49 \%$ were $17-20$ and $33 \%$ were $21-24$; half were male and half were female (Table 1, page 197). Forty-six percent were currently attending school, and the rest were either working or unemployed. More than nine in 10 either lived with both biological parents or were from intact families. The majority of respondents' fathers and mothers had a junior high school or high school education (including technical school). More than half of respondents had a high school education or had attended technical school, and one-fourth had at least a college education. Only 35\% had received any formal sex education. Finally, nearly equal proportions lived in rural or urban areas, while $46 \%$ lived in eastern China, 31\% in central China and 23\% in western China.

Five percent of males and 3\% of females aged 15-16 reported having had sexual intercourse by the time of the survey (Table 2, page 198). Among 17-20-year-olds, 17\% of males and $13 \%$ of females had had sex by this time, as had $46 \%$ and $39 \%$ of $21-24$-year-old males and females, respectively. Overall, $26 \%$ of males and $19 \%$ of females reported sexual debut by the time of the survey. Notably, lower proportions of respondents who were in school than of those who were working or unemployed reported ever having had sex (9-14\% vs. $28-35 \%)$. The proportions of those reporting sexual experience were roughly similar for males and females across educational levels; in each gender, the proportions who had had sex were similar regardless of whether they had received formal sex education (25-27\% for males, and 19-20\% for females). Similar proportions of rural and urban males reported sexual debut (25-26\%), and the same pattern held for females (18-20\%); likewise, $25-28 \%$ of male respondents in the different regions reported sexual debut, as did $19-20 \%$ of females.

Our preliminary life table analysis found that the mean age at sexual debut was 22.8 years for unmarried Chinese youth, and that males experienced debut at a younger age than females (22.5 vs. 23.1 years-not shown). Sexual debut before age 18 was rare for both males and females, as well as when examined by urban or rural residence and by region (Figures 1-3; differences in the survival plots in each figure are highly significant at $\mathrm{p}<.001$ ). Ages $21-24$ appear to be the normative stage in the life course for sexual debut. The timing of debut tended to be earlier for males than for females, and a greater proportion of males were 
sexually experienced at each year of age between 17 and 24 (Figure 1, page 199). For both genders, living in a rural area was associated with an earlier age of sexual debut: Rural males were less likely than urban males to remain virgins at ages 16-22, as were rural females compared with their urban counterparts at ages 15-21 (Figure 2). We also found regional differences in the proportions of males and females who remained virgins: Among males, the cumulative survival rate for ages 17-24 was lowest in western China and highest in eastern China, and among females, the same pattern held for ages 19-23 (Figure 3).

Using Cox proportional hazard regression analysis (results available upon request), we confirmed that gender was associated with the timing of sexual debut $(p<.001)$. When the background characteristics given in Table 3 were controlled for, males had a $30 \%$ greater risk of experiencing sexual debut than did females within each year of age.

In multivariate regression analysis, family structure was associated with the timing of sexual debut for both males and females (Table 3, page 202): Within each year of age, respondents from intact households with two biological parents had a 28-29\% lower risk of experiencing debut than did those from other family situations (e.g., singleparent households). A similar reduction in risk was found regarding fathers' educational level: Compared with males whose fathers had elementary schooling or less, those whose fathers had a junior or senior high school education had a 28-32\% lower risk of experiencing sexual debut. However, having a father with a college education was not associated with the timing of debut. In contrast, the risk of sexual debut was elevated at higher levels of maternal education: Males whose mothers were high school or college graduates had a $39-40 \%$ higher risk of debut within each year of age than did those whose mothers had no more than an elementary education. For females, those whose fathers had a junior high school education had a $28 \%$ lower risk of sexual debut in comparison with those whose fathers had only elementary schooling or less.

When respondents' education was considered, males and females who were college graduates had a lower risk of having experienced sexual debut within each year of age when compared with their counterparts who had no more than a junior high school education (by 30\% and 40\%, respectively). Receipt of formal sex education was not associated with the timing of debut for either gender.

Finally, both residence and region were associated with sexual debut. After controlling for other covariates, the risk of experiencing debut within each year of age was 19\% lower for urban males and 24\% lower for urban females than for their rural counterparts. Moreover, compared with males who lived in China's western region, those living in the eastern region had a 32\% lower risk of sexual debut.

\section{DISCUSSION}

The average age at sexual debut among Chinese youth-22.8 years-is higher than the average age typically found in Western societies, but it represents a decline
FIGURE 3. Survival distributions of sexual debut among Chinese youth, by gender and region

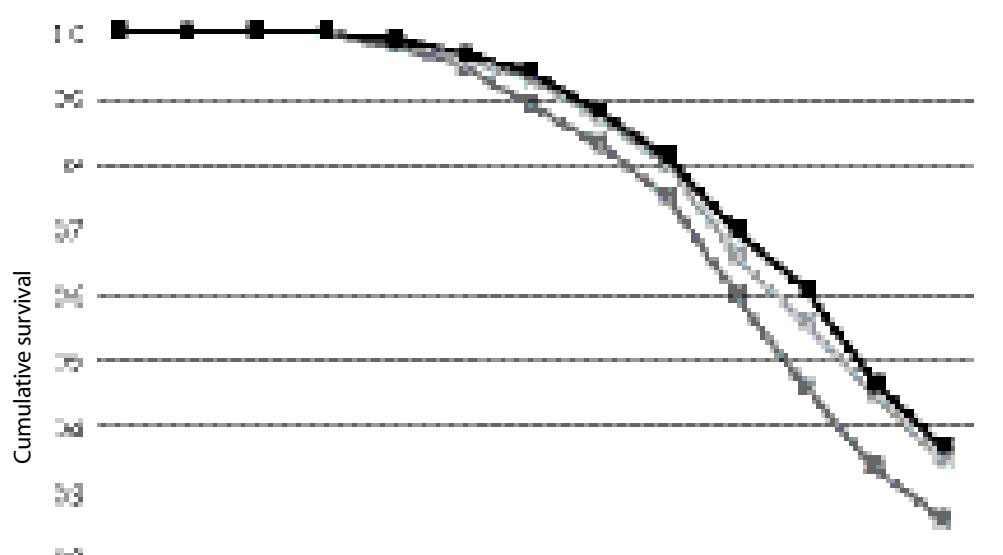

2

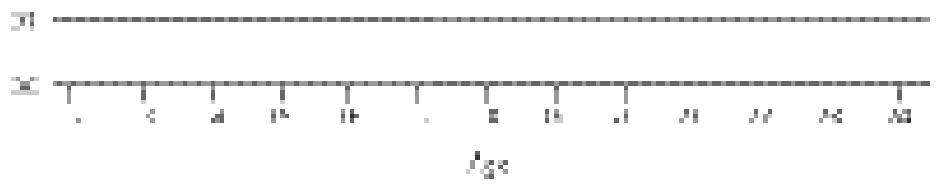

Mele

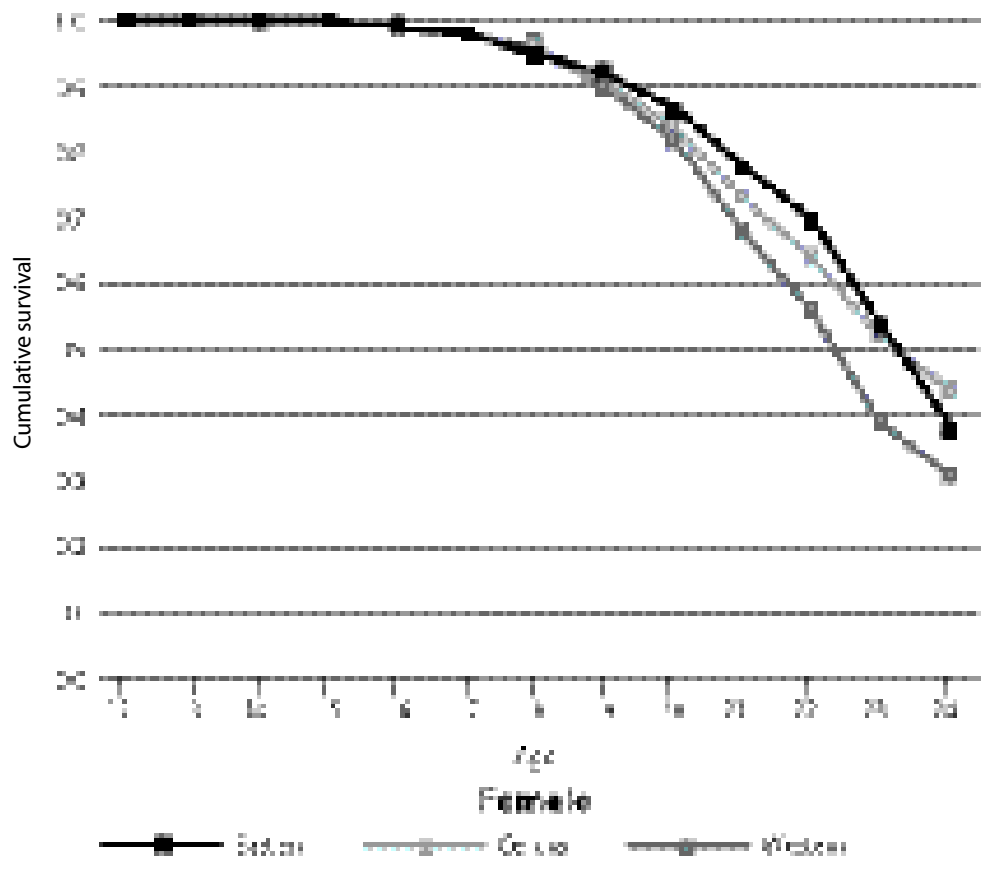

in age at debut compared with that of previous Chinese generations. ${ }^{12}$ This decline has occurred in the context of a moderation of societal attitudes toward premarital sex, which was taboo a generation ago. As discussed earlier, sexual intercourse has increasingly become delinked from marriage and procreation over the last several decades in China, and there is less social regulation of sexual behavior. The respondents in our study population, who were born after the "Open Door" policy and economic reforms began, have come of age in a relatively permissive sexual culture (according to Chinese standards), and this has pre- 
TABLE 3. Adjusted hazard ratios (and robust standard errors) from Cox proportional hazard regression analysis assessing respondents' risk of having experienced sexual debut, by gender, according to selected characteristics

Characteristic

Male

$(\mathrm{N}=2,868)$

Female

\section{Current activity}

In school

Working/unemployed (ref)

$1.09(0.86-1.38)$

1.00

1.00

Family structure

Household with both biological parents

Other (ref)

$0.72(0.55-0.95)^{*}$

1.00

$0.71(0.58-0.87)^{* *}$

1.00

\section{Father's education}

selementary school (ref)

Junior high school

Senior high/technical school $†$

zcollege

$\begin{array}{ll}1.00 & 1.00 \\ 0.72(0.52-0.99)^{*} & 0.72(0.53-0.98)^{*} \\ 0.68(0.48-0.97)^{*} & 0.72(0.50-1.06) \\ 0.77(0.51-1.18) & 0.91(0.60-1.38)\end{array}$

\section{Mother's education}

selementary school (ref)

Junior high school

Senior high/technical schoolt

zcollege

1.00

$1.19(0.97-1.47)$

$1.39(1.08-1.80)^{*}$

1.00

$1.40(1.04-1.88)^{*}$

$(0.88-1.24)$

$1.17(0.93-1.47)$

$1.14(0.79-1.64)$

Respondent's education

sjunior high school (ref)

Senior high/technical schoolt

zcollege

$\begin{array}{ll}1.00 & 1.00 \\ 1.06(0.92-1.21) & 1.08(0.91-1.27) \\ 0.70(0.58-0.80)^{* * *} & 0.60(0.46-0.79)^{* * *} \\ & \\ 1.10(0.95-1.27) & 1.04(0.86-1.25) \\ 1.00 & 1.00 \\ & \\ 1.00 & 1.00 \\ 0.81(0.70-0.94)^{* *} & 0.76(0.65-0.88)^{* * *}\end{array}$

Received formal sex education

Yes

No (ref)

Residence

Rural (ref)

Urban

$0.81(0.70-0.94)^{* *}$

$0.76(0.65-0.88)^{*}$

\section{Region}

Eastern

$0.68(0.46-0.99)^{*}$

$0.72(0.48-1.08)$

$0.78(0.50-1.22) \quad 0.80(0.49-1.33)$

Western (ref)

1.00

1.00

$\log L$

Model (Wald) chi-square

d.f.
$-17,314$

$117.47^{* * *}$

14

${ }^{*} \mathrm{p}<.05 .{ }^{* *} \mathrm{p}<.01 .{ }^{* * *} \mathrm{p}<.001$. fFor students who have finished junior high school. Note: ref=reference group.

sumably influenced their sexual behavior.

In China, sexual debut before age 18 is rare, and the significant proportion of young people who remain virgins at age 24 suggests that marriage is still an important context for sexual debut for many people.* In both communitylevel contexts examined here, females tend to postpone their sexual debut longer than males, which is consistent with our expectations and supports the notion that premarital sex has a greater cost for females. Earlier research suggests that the social climate remains less permissive of female sexuality than of male sexuality outside marriage. ${ }^{13}$ Indeed, females who appear to engage in regular premarital sex are perceived negatively, and this can lower their prospects on the marriage market. To some extent, this bias is also changing (especially the expectation of premarital virginity), but generally only insofar as it regards

*In 2000-2005, the average age at first marriage was 25 for women and 27 for men [source: Liu J and Zhao G, Gender and urban-rural differences in age at first marriage in China, Population \& Development, 2009, 15(4):13-21 (in Chinese)].

premarital sex for an engaged couple. ${ }^{5}$

Perhaps our most difficult finding to understand is the association of parental education with timing of sexual debut. For the most part, this relationship did not function in the expected direction, as we hypothesized that the risk of sexual debut would decline as the level of parental education increased. We found that parental education had a limited association with debut for females, and while paternal education appeared to show a protective relationship for males, maternal education showed the opposite. There is no reason to believe that parental education is not a reasonable indicator of socioeconomic status, especially since China's economy has become more market-oriented. The unexpected findings regarding parental education deserve further research.

We hypothesized that youth in urban areas would have a higher risk of sexual debut than those in rural areas, largely because this was where social change was centered. However, we found that rural respondents had an increased risk of sexual debut at nearly all ages. The most plausible explanation for this difference is the culture of early marriage in rural areas; indeed, the literature suggests that community settings that encourage early marriage also have an early onset of sexual activity. ${ }^{24}$ Furthermore, while premarital sex was once taboo in rural areas, a new cultural norm is emerging in which it has become increasingly common and socially acceptable for engaged couples. ${ }^{5}$ Given the younger age at engagement and marriage in rural areas, this could explain the difference in the timing of sexual debut between urban and rural youth. Finally, it is not clear why males from the more urban and modernized eastern region of China had a lower risk of sexual debut than those from the underdeveloped (and presumably more traditional) western region. This finding contradicts our assumption that the risk would be higher in the former region, and should be the subject of future research.

\section{Conclusions}

This national study addresses the previous lack of research on the timing of sexual debut among Chinese youth and provides insight into the basic patterns and social and demographic correlates of debut. Though this country's youth have a fairly late age at sexual debut in comparison with youth from other countries, they are not more informed about contraceptive use or STI prevention. Indeed, more than half of Chinese youth do not use contraceptives at sexual debut-which places them at increased risk of unwanted pregnancies and STIs ${ }^{19}$-and hence sex education and public health programs should be improved to address these shortcomings. This study also raises the issue of the risk of "early" sexual debut, and although debut is uncommon before age 18, a small proportion of youth do initiate sex by that age. This potentially vulnerable subpopulation merits future research attention regarding the determinants and consequences of their early transition to sexual experience. 


\section{REFERENCES}

1. Caron SL and Moskey EG, Changes over time in teenage sexua relationships: comparing the high school class of 1950, 1975, and 2000, Adolescence, 2002, 37(147):515-526

2. Bingham CR, Miller BC and Adams GR, Correlates of age at first sexual intercourse in a national sample of young women, Journal of Adolescent Research, 1990, 5(1):18-33.

3. Johnson KA and Tyler KA, Adolescent sexual onset: an intergenerational analysis, Journal of Youth and Adolescence, 2007, 36(7):939-949.

4. National Bureau of Statistics of China, The 2000 Census of China (in Chinese), <http://www.stats.gov.cn/tjsj/ndsj/renkoupucha/ 2000pucha/pucha.htm>, accessed Dec. 2, 2011.

5. Wang B and Davidson P, Sex, lies, and videos in rural China: a qualitative study of women's sexual debut and risky sexual behavior, Journal of Sex Research, 2006, 43(3):227-235.

6. Wang B et al., The potential of comprehensive sex education in China: findings from suburban Shanghai, International Family Planning Perspectives, 2005, 31(2):63-72.

7. Zhang L, Li X and Shah IH, Where do Chinese adolescents obtain knowledge of sex? Implications for sex education in China, Health Education, 2007, 107(4):351-363.

8. Song Y and Ji CY, Sexual intercourse and high-risk sexual behaviours among a national sample of urban adolescents in China, Journal of Public Health, 2010, 32(3):312-321.

9. World Health Organization (WHO), Sexual and Reproductive Health of Adolescents and Youth in China, Geneva: WHO, 2005.

10. Xiao Z, Mehrotra P and Zimmerman R, Sexual revolution in China: implications for Chinese women and society, AIDS Care, 2011, 23(Suppl. 1):105-112.

11. Tien HY, Age at marriage in the People's Republic of China, China Quarterly, 1983, 93:90-107.

12. Parish WL, Laumann EO and Mojola SA, Sexual behavior in China: trends and comparisons, Population and Development Review, 2007, 33(4):729-756.

13. Pan S, Transformations in the primary life cycle: the origins and nature of China's sexual revolution, in: Jeffreys E, ed., Sex and Sexuality in China, New York: Routledge, 2006.

14. Feng W and Quanhe Y, Age at marriage and the first birth interval: the emerging change in sexual behavior among young couples in China, Population and Development Review, 1996, 22(2):299-320.

15. Zha B and Geng W, Sexuality in urban China, Australian Journal of Chinese Affairs, 1992, 28:1-28.

16. Wu $\mathrm{Z}$ et al., Sex ratio at birth, marriage markets, and age at first marriage in China, paper presented at the International Symposium on Gender and Sustainable Social Development, Xi'an, China, Oct. 15-17, 2011.

17. Higgins LT et al., Attitudes to marriage and sexual behaviors: a survey of gender and culture differences in China and United Kingdom, Sex Roles, 2002, 46(3-4):75-89.

18. Wang B et al., Sexual attitudes, pattern of communication, and sexual behavior among unmarried out-of-school youth in China, BMC Public Health, 2007, Vol. 7, Art. 189, <http://www. biomedcentral.com/content/pdf/1471-2458-7-189.pdf>, accessed Sept. 28, 2012

19. Zheng XY, Chen G and Gao CL, Preliminary findings of first National Youth Reproductive Health Survey, unpublished manuscript, Beijing: Institute of Population Research, Peking University, 2010

20. Chen XS et al., Epidemiologic trends of sexually transmitted diseases in China, Sexually Transmitted Diseases, 2000, 27(3):138142.
21. Li Y et al., Needs and preferences regarding sex education among Chinese college students: a preliminary study, International Family Planning Perspectives, 2004, 30(3):128-133.

22. Jessor $\mathrm{R}$ et al., Time of first intercourse: a prospective study, Journal of Personality and Social Psychology, 1983, 44(3):608-626.

23. Meschke LL et al., Demographic, biological, psychological, and social predictors of the timing of first intercourse, Journal of Research on Adolescence, 2000, 10(3):315-338.

24. Day $\mathrm{RD}$, The transition to first intercourse among racially and culturally diverse youth, Journal of Marriage and the Family, 1992, 54(4):749-762.

25. Upchurch DM et al., Inconsistencies in reporting the occurrence and timing of first intercourse among adolescents, Journal of Sex Research, 2002, 39(3):197-206.

26. Singh S et al., Gender differences in the timing of first intercourse: data from 14 countries, International Family Planning Perspectives, 2000, 26(1):21-28.

27. Hawes ZC, Wellings $\mathrm{K}$ and Stephenson J, First heterosexual intercourse in the United Kingdom: a review of the literature, Journal of Sex Research, 2010, 47(2):137-152.

28. Blum RW et al., The effects of race/ethnicity, income, and family structure on adolescent risk behaviors, American Journal of Public Health, 2000, 90(12):1879-1884.

29. Young EW et al., The effects of family structure on the sexual behavior of adolescents, Adolescence, 1991, 26(104):977-986.

30. Santelli JS et al., The association of sexual behaviors with socioeconomic status, family structure, and race/ethnicity among US adolescents, American Journal of Public Health, 2000, 90(10):15821588

31. Newcomer S and Udry JR, Parental marital status effects on adolescent sexual behavior, Journal of Marriage and the Family, 1987. 49(2):235-240

32. Xu A, Zhang J and Xia YR, Impacts of parents' divorce on Chinese children, Marriage E Family Review, 2008, 42(3):91-119.

33. Hofferth SL, Factors affecting initiation of sexual intercourse, in: Hofferth SL and Hayes CD, eds., Risking the Future: Adolescent Sexuality, Pregnancy, and Childbearing, Washington, DC: National Academy Press, 1987.

34. Kohler PK, Manhart LE and Lafferty WE, Abstinence-only and comprehensive sex education and the initiation of sexual activity and teen pregnancy, Journal of Adolescent Health, 2008, 42(4):344-351.

35. Mueller TE, Gavin LE and Kulkarni A, The association between sex education and youth's engagement in sexual intercourse, age at first intercourse, and birth control use at first sex, Journal of Adolescent Health, 2008, 42(1):89-96.

36. Liu Z, Institution and inequality: the hukou system in China, Journal of Comparative Economics, 2005, 33(1):133-157.

37. Fan CC, Of belts and ladders: state policy and uneven regional development in post-Mao China, Annals of the Association of American Geographers, 1995, 85(3):421-449.

38. Zhou X, Virginity and premarital sex in contemporary China, Feminist Studies, 1989, 15(2):279-288.

39. Liu $\mathrm{H}$ et al., A study of sexual behavior among rural residents of China, Journal of Acquired Immune Deficiency Syndromes and Human Retrovirology, 1998, 19(1):80-88.

40. Briere J, Methodological issues in the study of sexual abuse effects, Journal of Consulting and Clinical Psychology, 1992, 60(2):196203.

41. Eisenhardt KM, Building theories from case study research, Academy of Management Review, 1989, 14(4):532-550. 
42. Kaestle CE et al., Young age at first sexual intercourse and sexually transmitted infections in adolescents and young adults, American Journal of Epidemiology, 2005, 161(8):774-780.

43. Lohman BJ and Billings A, Protective and risk factors associated with adolescent boys' early sexual debut and risky sexual behaviors, Journal of Youth and Adolescence, 2008, 37(6):723-735.

44. Sandfort TG et al., Long-term health correlates of timing of sexual debut: results from a national US study, American Journal of Public Health, 2008, 98(1):155-161.

45. Institute of Population Research, Final Report on the 2009 National Youth Reproductive Health Survey, Beijing: Institute of Population Research, Peking University, 2010

46. Siegel DM, Aten MJ and Roghmann KJ, Self-reported honesty among middle and high school students responding to a sexual behavior questionnaire, Journal of Adolescent Health, 1998, 23(1):2028

47. Cox DR, Regression models and life-tables, Journal of the Royal Statistical Society. Series B. Methodological, 1972, 34(2):187-220.

\section{RESUMEN}

Contexto: La edad de la primera relación sexual está en descenso en la China, pero se sabe poco sobre la relación entre las características sociales y demográficas de la juventud china y el momento del debut sexual.

Métodos: Se obtuvieron datos de la Encuesta Nacional de Salud Reproductiva en Jóvenes, llevada a cabo en 2009, la cual recolectó información sobre los antecedentes y la edad del primer coito de 22,300 jóvenes no casados en edades de 15-24 años. Se usó análisis de tablas de vida para estimar las distribuciones especificas del debut sexual por edades en hombres y mujeres, según la residencia urbana o rural y por región. Posteriormente, se emplearon modelos de regresión de riesgo proporcional de Cox para identificar las características asociadas con el momento del debut sexual en hombres y mujeres.

Resultados: La edad promedio del debut sexual fue de 22.8 años (22.5 años para los hombres y 23.1 años para las mujeres). El debut sexual antes de los 18 años de edad fue poco común para ambos, hombres y mujeres; y las edades de 21-24 parecen ser el rango normativo para el primer coito. El análisis de tablas de vida reveló que el debut era más temprano para los hombres que para las mujeres; también, para las personas viviendo en un área rural que para aquellas en áreas urbanas; y para las personas en el oeste del país que para las personas en otras regiones. En el análisis multivariado, los hombres tuvieron un riesgo el 30\% más alto que las mujeres de tener su debut sexual en cada año de edad estudiado. El hecho de vivir con ambos padres biológicos, el tener un padre con un grado de educación secundaria básica o superior, ser graduado universitario y vivir en un área urbana, estuvieron asociados con un menor riesgo del debut sexual.

Conclusión: Este estudio proporciona conocimientos acerca del debut sexual en jóvenes chinos, así como los patrones básicos y de los factores sociales y demográficos correlacionados.

\section{RÉSUMÉ}

Contexte: L'âge au moment des premiers rapports sexuels diminue en Chine. On en sait cependant peu sur la relation entre les caractéristiques sociodémographiques des jeunes $d u$ pays et le moment de ces premiers rapports.

Méthodes: Les données sont issues de l'Enquête nationale de 2009 sur la santé reproductive des jeunes, à l'occasion de laquelle les caractéristiques socioculturelles et l'âge au moment des premiers rapports sexuels de 22.300 jeunes non mariés de 15 à 24 ans ont été recueillis. Les distributions sexospécifiques des premiers rapports sexuels par âge, en fonction du lieu de résidence urbain ou rural et par région ont été estimées par analyse des tables de mortalité. Des modèles de régression proportionnels de risques de Cox ont ensuite servi à identifier les caractéristiques associées au moment des premiers rapports sexuels côté masculin et féminin.

Résultats: L'âge moyen aux premiers rapports sexuels est de 22,8 ans (de 22,5 ans pour les hommes et de 23,1 ans pour les femmes). Les premiers rapports avant l'âge de 18 ans sont rares dans les deux sexes et les âges de 21 à 24 ans semblent être la norme. L'analyse des tables de mortalité révèle que les premiers rapports sexuels interviennent plus tôt chez les hommes, dans les milieux ruraux et dans la région occidentale de la Chine. Dans l'analyse multivariée, les hommes sont associés à un risque de premiers rapports supérieur de 30\% à chaque année d'âge par rapport aux femmes. Vivre avec ses deux parents biologiques, avoir un père doté d'une éducation secondaire de premier ou de deuxième cycle, avoir un diplôme universitaire et vivre en milieu urbain sont les facteurs associés à une moindre probabilité d'avoir vécu ses premiers rapports sexuels

Conclusion: Cette étude révèle les grandes tendances et les corrélats sociodémographiques du début de l'activité sexuelle des jeunes de Chine.

\section{Acknowledgments}

The authors gratefully acknowledge support from a Social Sciences and Humanities Research Council grant, China's National "973" project on Population and Health (2007CB5119001) and a China Scholarship Council grant (2010601193), as well as research assistance from Christoph M. Schimmele.

Author contact: xzheng@pku.edu.cn 